Journal of Economics and Behavioral Studies

Vol. 4, No. 5, pp. 252-260, May 2012 (ISSN: 2220-6140)

\title{
The Influence of Personality Traits on Mobile Phone Application Preferences
}

\author{
*Wilburn Lane, Chris Manner \\ McAfee School of Business Administration Union University, USA \\ *wlane@uu.edu
}

\begin{abstract}
Understanding mobile phone users' preferences and behavior is essential for the commercial success of new application development. This study aims to enhance this understanding by identifying the personality traits associated with smart phone application use. Multiple regressions were used to analyze results from a sample of 233 participants. Consistent with recent personality research, we found that the "Big Five" personality dimensions are related to the application of smartphone technology. Extroverted individuals reported greater importance on gaming applications, but they viewed productivity applications as less important. Also, neurotics placed greater importance on travel applications, while less conscientious people indicated that communication, productivity, and utilities applications were less important to them.
\end{abstract}

Keywords: Personality Traits, Mobile Phone Applications, Big Five Inventory, Extraversion, Conscientiousness

\section{Introduction}

The smartphone has become the great communicator of the twenty-first century. Its growth is phenomenal. The CNN website reported that 269.9 million smartphones were purchased internationally in 2010 (Weintraub, 2010). Morgan Stanley Research forecasts that smartphone sales will exceed those of the PC in 2012 (Brownlow, 2011). Gartner, Inc. predicts that by 2013 smartphones will surpass the PC as the most common way to access the web (Whitney, 2011). The tremendous increase in smartphone ownership has created a new industry--the mobile phone app (short for application). The App Store (Apple's store for purchasing applications for the iPhone) has an inventory of more than 500,000 mobile phone applications and the other manufacturers of smartphones are encouraging the development of apps for their phones as well. Entrepreneurs all over the world are continually developing new apps. The cost of developing a new app can range from $\$ 15,000-20,000$ for a simple app to over a $\$ 100,000$ for a more complicated one.

The App Store gives the owner of the app 70\% of the revenue generated by the app (Phillips, 2010). This makes the development of apps very profitable. Many retail and not-for-profit organizations have developed apps to alert customers of potential buying opportunities and to facilitate the customer's interaction with the organization. Smartphone applications have dramatically increased revenue in mobile marketing. According to BIA/Kelsey, total U. S. mobile ad spending will grow from $\$ 790$ million in 2010 to $\$ 4$ billion in 2015. Even more striking is that most of this growth is going to be in local content advertising, which is expected to grow from $\$ 404$ million to $\$ 2.8$ billion. This makes locally targeted mobile ads 51 percent of overall U.S. mobile advertising spending now, but by 2015 , it will be 70 percent of mobile advertising spending (U.S. Mobile, 2011). While print media continue to struggle and as broadcast media become more fragmented, mobile advertising spending appears to be the way more and more organizations will communicate with their customers, and this is especially true on the local level. As more and more smartphone applications are developed and as the number and kind of organizations using smartphone applications to communicate with their constituencies grows, it is imperative that the application developers understand why certain people are more likely to use specific types of applications and what they expect of an application. With literally hundreds of thousands of applications at the fingertips of the smartphone user, developers must differentiate themselves from the competition if they are going to have a successful application. The purpose of this study is to determine if different personality types are more likely to use certain types of smartphone applications, examine why they may be attracted to certain kinds of apps, and explore how this information may be used by the marketer to promote his app or to sell ads on his app. 


\section{Literature Review}

While the smartphone application industry is a relatively new industry, some demographic data have been collected regarding these types of applications. Researchers have found that gender plays a role in the types of apps people use. Women are more likely to play mobile social games than they are to play traditional games such as Wii, Xbox 360 and PlayStation 3. Males comprise $60 \%$ of the traditional gamers' market but only $47 \%$ of the mobile social gamers' market (Mobile Social Gamer, 2011). Women are more likely to rely on social networking apps such as Facebook and Twitter while men are more likely to use productivity and financial apps (Greengard, 2010). Age also influences the type of apps people use. The mobile social gamer tends to be younger, average age of 28, than the traditional gamer--average age of 34 (Mobile Social Gamer, 2011). While the $18-29$ year olds comprise only $23 \%$ of the population, they constitute $44 \%$ of the appsusing population (Greengard, 2010). In contrast, $41 \%$ of the adult population is age 50 and older, but make up only $14 \%$ of the app-using population (Greengard, 2010). Younger adopters also use apps, including games and social media, more frequently (Greengard, 2010). While some demographic data have been collected regarding the demographic characteristics of apps users, the influence of personality traits has largely been ignored. This study used the "Big Five Inventory" to determine if the five traits identified in this inventory influence the type of smartphone applications people use. The five traits examined are extraversion, conscientiousness, agreeableness, neuroticism, and openness to experience. Extraverts are described as being sociable, gregarious, and ambitious. They are optimistic and seek out new opportunities and excitement (McElroy, et al. 2007). Those high in extraversion are social, active, and outgoing, and place a high value on close and warm interpersonal relationships (Watson and Clark, 1997). Devaraj et al. (2008) found that extraversion moderated the relationship between subjective norms and intentions to use technology such that the relationship is stronger for individuals with higher extraversion. Ehrenberg et al. (2008) found that extraverted individuals spent more time texting. Those high in extraversion are naturally inclined to care about their image and other social consequences of behaviors, and therefore are more likely to form intentions to act based upon their perceptions of the opinions of significant others (Devaraj et al. 2008). Extraverts are more likely to own a smartphone and place greater importance on texting (Lane and Manner, 2011).

The hallmark of the conscientious personality is self-control, reflected in a need for achievement, order, and persistence (Costa et al, 1991). They are strong-willed, deliberate, and reliable (McElroy et al. 2007). Devaraj et al. (2008) found that conscientiousness moderates the relationship between perceived usefulness of technology and intention to use technology such that the relationship was stronger for individuals with higher conscientiousness. Conscientious people look for ways in which the use of technology would allow them to be more efficient and perform at a higher level at work (Barrick and Mount, 1991). People who score high on agreeableness are sympathetic, good natured, cooperative and forgiving (McElroy et al. 2007). Agreeable people do well in jobs that involve considerable interpersonal interaction and teamwork (Barrick et al. 2001). Devaraj et al. (2008) found that agreeableness is positively associated with beliefs about the perceived usefulness of technology. Phillips et al. (2006) discovered that people low on agreeableness were more likely to use their phones to play games. Ehrenberg et al. (2008) found that more disagreeable individuals spend more time on calls and that disagreeable individuals with lower self-esteem spent more time using instant messaging and reported stronger instant messaging addictive tendencies. Agreeable place greater importance on making phone calls and less importance on texting (Lane and Manner, 2011). Neurotic people tend to be anxious, self-conscious and paranoid (Devaraj et al. 2008). Highly neurotic people tend to be fearful, sad, embarrassed, distrustful, and have difficulty managing stress (McElroy et al. 2007). Ehrenberg et al. (2008) found that neurotic individuals spent more time text messaging and reported stronger mobile phone addictive tendencies. Neurotic personalities are likely to view technological advances in their work as threatening and stressful, and to have generally negative thought processes when considering technological advances (Devaraj et al. 2008).

Those who score high in openness actively seek out new and varied experiences and value change (McCrae and Costa, 1997). Open individuals tend to devise novel ideas, hold unconventional values, and willingly

question authority (Costa and McCrae, 1992). Devaraj, et al. (2008) concluded that individuals high in openness are more likely to hold positive attitudes and cognitions toward accepting job-related technology in 
part because of their predisposition to embrace new approaches to work and they are less threatened by change implied in adopting technology. Digman (1990) states that these factors theoretically capture the essence of one's personality. Barrick et al. (2001) declared that it is the most useful taxonomy in personality research. Briggs (1992) refers to it as "the model of choice for the researcher wanting to represent the domain of personality variables broadly and systematically." Costa and McCrae (1992) indicate that it is the most comprehensive and parsimonious model of personality. McElroy (2007) found that it was a better predictor of personality indicators for technology related issues than the Myers-Briggs Type Indicator (MBTI). Since there are already hundreds of thousands of smartphone apps and more are being created every day, we need a better understanding of what apps are being used and why. The purpose of this study is to examine the influence personality traits may have on the type of smartphone applications people use. We know that certain personality types are more likely to embrace technology, and we know that certain types of personalities are more likely to own a smartphone. In addition, we know that different personality types are more likely to place more importance on different smartphone functions, such as making calls, texting, emailing, etc. Therefore, it is logical to assume that different personality types are more likely to place more importance on different categories of smartphone apps.

\section{Methodology}

Participants: A total of 750 questionnaires were distributed electronically to a sample of participants who were recruited using social networking and various online techniques. Of these, 448 were returned giving an adequate response rate of $59.7 \%$. Involvement was restricted to those who owned mobile phones and who were 18 years of age and older. After deleting those with missing data, the final sample had 312 participants ( $60 \%$ female, $40 \%$ male). Age ranged from 18 to 77 years with a median age of 41 and a mean age of 40 . Over half of the respondents had at least a 4-year degree. Twenty-seven percent of the respondents were minorities. There were 233 respondents who indicated they owned a smartphone. Although the sample was a convenience sample, efforts were made to solicit respondents that were diverse in regard to gender, age, and ethnicity.

Materials: The study focused on consumers who owned and utilized the functions of a smartphone. Consequently, participants were asked if they owned a mobile phone that could download and process information, such as an iPhone, Droid, or Blackberry. Respondents who owned a smartphone were then asked to rate on a five-point scale (1, not important at all, to 5, very important) the importance of the six categories of smartphone applications recognized by the Mobile Marketing Association: communications, games, multimedia, productivity, travel, and utilities. These categories are described below in Table 1 (Mobile Applications, Table 2, 2008).

Personality type was measured using John's (1991) Big Five Personality Inventory. Although somewhat inferior to standard multi-item scales, this instrument has shown significant convergence with more widely used Big Five measures. Furthermore, this scale was used to enhance response rate because it only takes a few minutes. Coefficient alphas for the scales used in this study ranged from 0.74 for Conscientiousness to 0.86 for Extraversion.

Procedure: From March 2011 to May 2011, participants were sent e-mails containing a hyperlink to Qualtrics, a commercial survey-hosting Web site. Participants then logged onto the survey site and entered their answers. The data were downloaded in raw form, screened for anomalies, and analyzed using PASW 18.0 statistical software (SPSS, Inc., Chicago, IL). An ordinary least square (OLS) linear regression analyses was conducted to determine which personality traits influenced the perception of different smartphone application categories.

\section{Results}

The means, standard deviations, minimum and maximum values, and the skew for the independent variables are shown in Table 2. An inspection of the independent variables revealed that agreeableness and conscientiousness were negatively skewed. Consequently, these scales were inverted by subtracting them 
from their maximum value plus one before transformation. A square root transformation was then used on the inverted scales. Due to the inversion, these variables were renamed "lo-agreeableness" and "loconscientiousness" to help interpretation.

\section{Table 1: Mobile Application Types}

\section{Communications:}

E-mail Clients

IM Clients

Mobile Web and Internet Browsers

News/Information Clients

On-Device Portals (Java Portals)

Social Network Clients

Games:

Puzzles/Strategy (e.g., Tetris, Sudoku, Chess

Cards/Casino (e.g. Solitaire, Blackjack, Roulette, Poker)

Action/Adventure (e.g. Doom, Pirates of the Caribbean, Role-Playing Games)

Sports (e.g. Football, Soccer, Tennis Basketball, Racing, Boxing, Skiing)

Leisure Sports (e. g. Bowling, Pool, Darts, Fishing, Air Hockey)

Multimedia:

Graphics/Image Viewers

Presentation Viewers

Video Players

Audio Players

Streaming Players (Audio/Video)

Productivity:

Calendars

Calculators

Diary

Notepad/Memo/Word Processors

Spreadsheets

Directory Services (e.g., yellow pages)

Banking/Finance

Travel:

City Guides

Currency Converters

Translators

GPS/Maps

Itineraries/Schedules

Weather

\section{Utilities:}

Profile Manager

Idle Screen/Screen Savers

Address Book

Task Manager

Call Manager

File Manger

To test for multicollinearity, Pearson's correlations were run on the variables employed in the study after transformation, and are presented in Table 3. Although several significant correlations were evident, all correlations were well below the selection criteria of 0.99 (Tabachnick and Fidell, 2000). Hence, the assumption of little or no multicollinearity in the sample was met. 
Table 2: Descriptive Statistics for the Extraversion, Openness to Experience, Agreeableness, Neuroticism, and Conscientiousness Scales

\begin{tabular}{lccccc}
\hline Predictors & Mean & Std Deviation & Minimum & Maximum & Skewness \\
\hline Extraversion & 21.14 & 5.27 & 7 & 30 & -0.26 \\
Openness & 19.15 & 3.59 & 5 & 25 & -0.61 \\
Agreeableness & 21.00 & 3.06 & 5 & 25 & -1.20 \\
Neuroticism & 20.01 & 5.49 & 8 & 38 & 0.19 \\
Conscientiousness & 17.82 & 2.02 & 4 & 20 & -1.63 \\
\hline
\end{tabular}

Means and standard deviations were calculated for the dependent variables, along with minimum and maximum values and skew. The results are presented in Table 3. Since the communications variable was negatively skewed, a square root transformation was applied after the score was inverted, reducing the skew to achieve the assumption of normality. Once again, the variable was renamed "lo-communications" to indicate inversion and assist with interpretation.

Table 3: Descriptive Statistics for the Importance of Smartphone Applications

\begin{tabular}{lccccc}
\hline $\begin{array}{l}\text { Dependent } \\
\text { Variable }\end{array}$ & Mean & $\begin{array}{c}\text { Standard } \\
\text { Deviation }\end{array}$ & Minimum & Maximum & Skewness \\
\hline Communications & 4.54 & 0.71 & 1 & 5 & -1.38 \\
Games & 2.72 & 1.04 & 1 & 5 & 0.59 \\
Multimedia & 3.47 & 1.03 & 1 & 5 & -0.15 \\
Productivity & 4.34 & 0.78 & 1 & 5 & -0.90 \\
Travel & 4.10 & 0.81 & 1 & 5 & -0.76 \\
Utilities & 4.16 & 0.90 & 1 & 5 & -0.94 \\
\hline
\end{tabular}

Multiple regression was used to determine how much, comparatively, the Big Five personality factors help explain mobile phone applications use. Specifically, we estimated six models in which the dependent variables were the self-reported importance of communications, games, multimedia, productivity, travel, and utility apps. The results are reported in Table 4. Extraversion was positively related to games and negatively related to productivity. Lo-agreeable people were more likely to report greater importance of utilities apps. Conversely, those who tend to be cooperative and good-natured placed less importance on screen savers, address books, and task manager apps. Neuroticism was positively correlated with travel. Loconscientiousness was a positive predictor of lo-communications and a negative predictor of productivity and utilities. That is, conscientious people reported a higher preference for mobile phone applications that are work-related. Openness to experience was not significantly correlated with any of the applications types.

Discussion and Implications: This present study sought to identify personality traits associated with smartphone applications use. Consistent with current trends in personality research (e.g., Devaraj et al 2008, Lane and Manner, 2011); this study found that the Big Five personality dimensions are related to the application of smartphone technology. Extraverts reported greater importance on gaming apps and less importance for productivity apps. As extraverts are recognized as being gregarious and having an extensive social network, one might expect that extraverts would have a greater preference for communications apps; however, this study did not find this to be the case. Bianchi and Phillips (2005) suggested that extraverts use their mobile phones for self-stimulatory purposes rather than socialization. This may explain why this study found that extraversion was positively correlated with the use of gaming apps. Also, games played using mobile technology need not necessarily be a solitary pursuit. Many commercially available gaming apps can be played in multi-player mode. Extraverts may have a preference for these types of games. Unfortunately, this present study did not specify the type of mobile phone game used.

Conscientiousness represents the tendency to be self-disciplined, strong-willed, deliberate, and reliable. Conscientious people actively plan, organize, and carry out tasks. As suggested by McElroy et al (2007), conscientious people are less likely to use mobile technology for what they see as unproductive activities. 


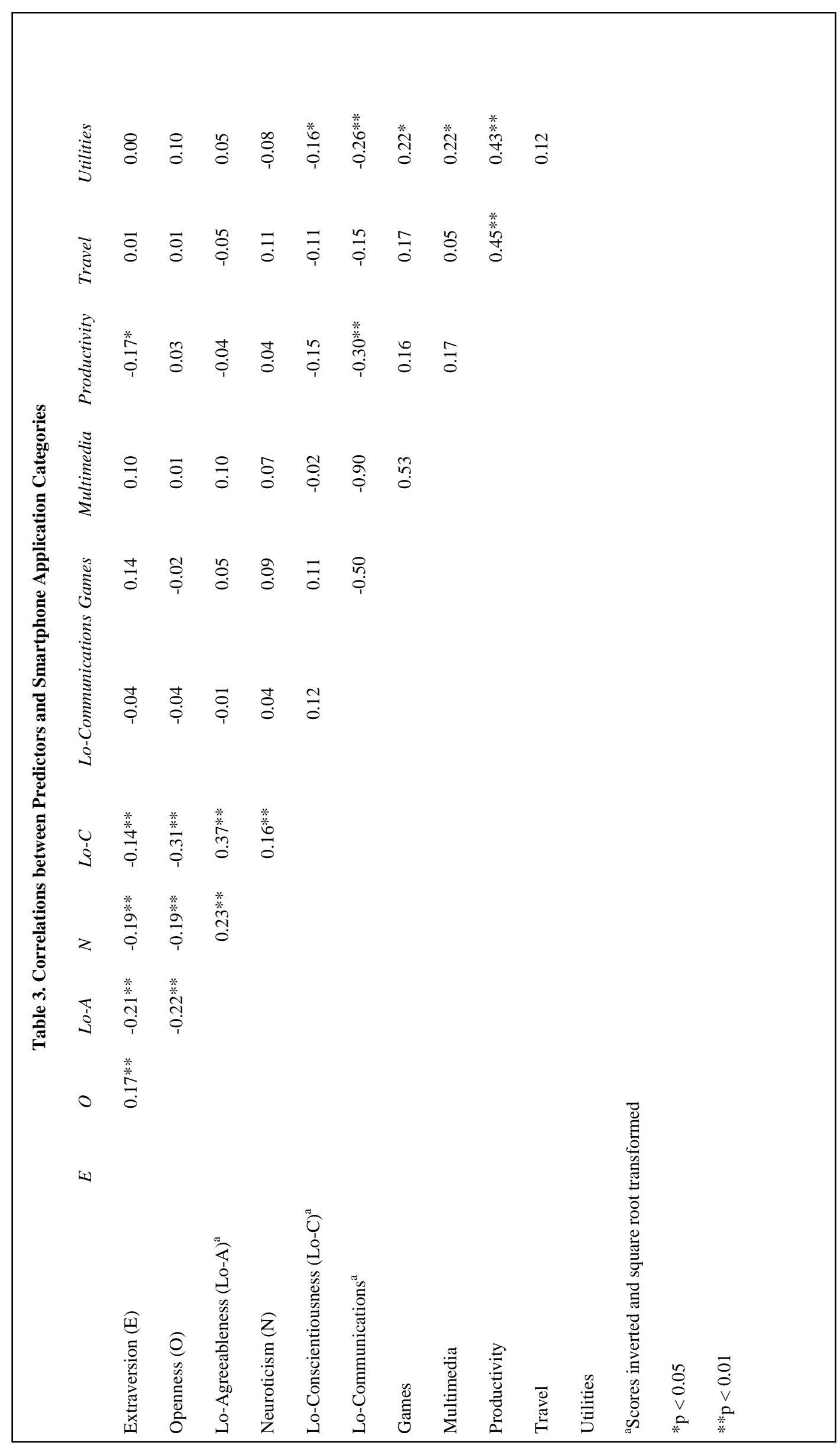




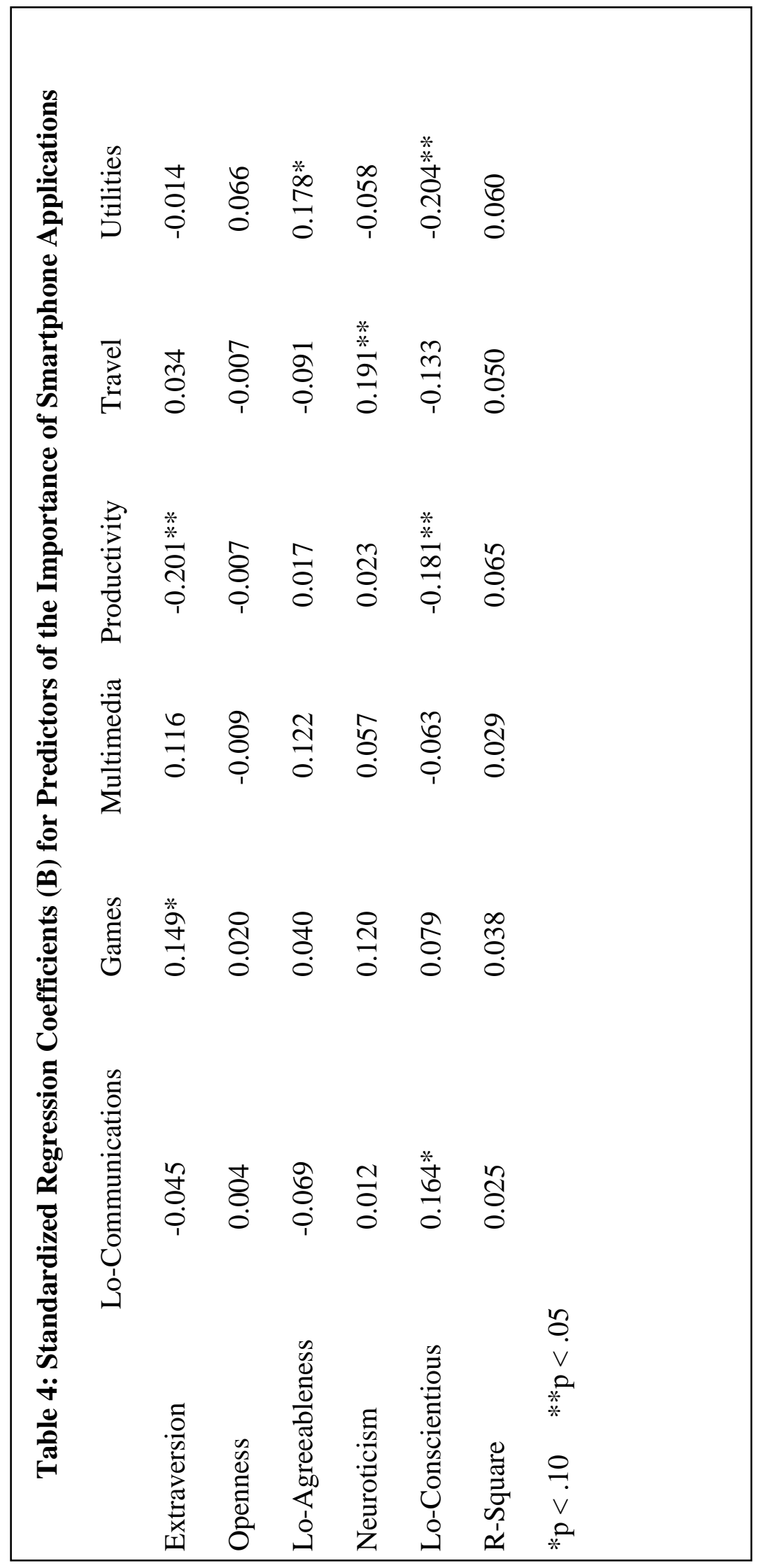


The findings of this study support this hypothesis, as less conscientious people reported significantly less importance on communications, productivity, and utilities apps. Neurotics place more importance on travel apps (i.e. GPS, weather, maps, itineraries, etc). This would be consistent with neurotics being fearful (McElroy et al. 2007). They use these apps to overcome their fear of being lost or of not being prepared for changing weather conditions. They can also use these apps to reduce their tendencies to be anxious and paranoid (Devaraj et al. 2008). If they know where they are and can see where they are going, they are not lost. If they know what the weather is going to be, they can prepare for it. Since Ehrenberg et al. (2008) found that neurotic individuals reported stronger mobile phone addictive tendencies, it would be logical for them to use smart phone apps to help them overcome or minimize these negative personality tendencies.

The findings of this study have several theoretical and practical implications. On the theoretical front, they highlight the role of individual differences and personality on mobile phone application preferences. Hopefully, this study will spur future researchers to examine the importance of other individual characteristics (i.e., education, income, gender, etc.) in determining the use and choice of mobile phone apps. Several studies have investigated the impact of personality on mobile technology and use. This study is a natural extension of that line of research. As for practical implications, when product managers or marketers in the mobile phone communications sector recognize the determinants of smartphone application use, they can understand the consumer's decision process in a more detailed manner. As such, they could develop new products according to consumers' needs and promote their innovations in an effective way. For example, neurotics were found to be more likely to use travel apps. Since neurotics are fearful, the marketer can emphasize how his GPS app will help the customer get to an unfamiliar place without getting lost.

Another practical implication of this study involves the delivery of advertising with and within mobile applications. Although still in its early stages, providing ads as part of mobile applications creates new revenue opportunities for application publishers, distributors, and service providers. Taking advantage of mobile application advertising requires a sound knowledge of the respective usage patterns (i.e., why, when, and how an audience uses a particular mobile application). For example, since neurotics are more likely to use travel apps, this would be a good place for insurance companies to advertise their product and to emphasize how their products can be useful in fearful times such as automobile accidents, natural disasters, and/or the death of a love one.

Limitations and Directions for Future Research: The results of this study must be viewed in light of its limitations. First, participant behavior was self-reported during a single session. Consequently, commonmethod bias is a potential weakness. Future researchers could test for this bias by using a larger sample. Ideally, in addition, future researchers should measure smartphone use behaviorally. Second, even though the literature suggests the Big Five Inventory is the best instrument to use for measuring personality traits when studying the use of technology, there are other instruments that might be employed (i.e. Myers-Briggs). Overall, personality was a fairly weak predictor of the importance of different types of smartphone apps. As such, future researchers should consider other factors that might predict the use of smartphone apps. Additional potential weaknesses of this study involve the sample itself. The sample size was relatively small. Also, potential sampling biases present an obvious threat to the generality of our findings. While measures were taken to ensure minimum representation according to certain demographic categories (i.e. age, gender, and ethnicity), the sample was not truly random. Since the questionnaire was only available through the Internet, the respondent pool was limited to those who had Internet access. It is difficult to determine if the results would have been different if those who did not have access to the Internet had responded to the questionnaire. However, given that the results of this study were generally consistent with mobile technology studies that did not rely on access to the Internet; we believe this limitation is of little concern. Finally, this study examined the effect of personality on the use of broad categories of smartphone apps. Future research should examine the relationship between personality and more specific apps, such as Facebook, The Weather Channel, and Angry Birds. Despite these limitations, the findings of this study have implications for both practitioners and academics. For example, findings from this research may help application developers and mobile telecommunication company's better target their products. Although this study is exploratory in nature, it is a contribution to the research on consumers' use of mobile devices as it suggests that personality provides a promising avenue for such research. 


\section{References}

Barrick, M. R. \& Mount, M. K. (1991). The big five personality dimensions and job performance: A metaanalysis. Personnel Psychology, 44(1), 1-26.

Barrick, M. R., Mount, M. K. \& Judge, T. A. (2001). Personality and performance at the beginning of the new millennium: What do we know and where do we go next? International Journal of Selection and Assessment, 9(1-2), 9-30.

Bianchi, A. \& Phillips, J. K. (2005). Psychological predictors of problem mobile phone use. Cyber Psychology \& Behavior, 8, 39-51.

Briggs, S. R. (1992). Assessing the five-factor model of personality description. Journal of Personality, 60(2), 253-293.

Brownlow, M. (2011). Smartphone sales and statistics. Email Marketing Reports. Retrieved from http://www.email-marketing-reports.com/wireless-mobile/smartphone- statistics.htm.

Costa, P. T. \& McCrae, R. R. (1992). Revised neo personality inventory_neo pi-r_and neo five-factor inventory _neo-ffi_professional manual. Odessa, FL: Psychological Assessment Resources.

Devaraj, S., Easley, R. F. \& Crant, J. M. (2008). How does personality matter? Relating the five factor model to technology acceptance and use. Information Systems Research, 19 (1), 93-105.

Digman, J. M. (1990). Personality structure: emergence of the five- factor model. Annual Review of Psychology, 41 (1), 417-440.

Ehrenberg, A. S., Juckes, K. M., White, H. \& Walsh, S. P. (2008). Personality and self-esteem as predictors of young people's technology use. Cyber Psychology and Behavior, 11(6), 739-741.

Entner, R. (2010). Smartphones to overtake feature phones in U.S. by 2011. Retrieved from http://blog.nielsen.com/nielsenwire/consumer/smartphones-to-overtake-feature-phones- in-u-s by- 2011.

Greengard, S. (2010). The Pew Report on Mobile Apps. Communications of the ACM, 51(11), 17. Retrieved from http://www.webopedia.com/TERM/M/mobile_application.html

John, O. P. (1990). The 'Big Five' factor taxonomy: Dimensions of personality in natural language and in questionnaires. In L. Pervin (Ed.), Handbook of Personality: Theory and Research. 56-100, New York: Guilford Press.

Lane, W. \& Manner, C. (2011). The impact of personality traits on smartphone ownership and use. International Journal of Business and Social Science, 2(17), 22-28.

McCrae, R. R. \& Costa P. T. (1997). Conceptions and correlates of openness to experience. In R. Hogan, J. Johnson, \& S. Briggs, Handbook of personality psychology (825-847). San Diego: Academic Press.

McElroy, J. C., Hendrickson, A. R., Townsend, A. M. \& DeMarie, S. M. (2007). Dispositional factors in internet use: personality versus cognitive style. MIS Quarterly, 31(4), 809-820.

Mobile Applications. (2008). Mobile Marketing Association. Retrieved from http://www.google.com/url?sa=t\&rct=j\&q=\&esrc=s\&source=web\&cd=1\&ved=0CFUQFjAA\&url=http \%3A\%2F\%2Fwww.mmaglobal.com\%2Ffiles\%2Fmobileapplications.pdf.

Mobile Social Gamers. (2011). The-New-Mass-Market-Powerhouse. Mobile Social Gamers. Retrieved from http://blog.flurry.com/bid/57219/Mobile-Social-Gamers

Phillips, J. G., Butt, S. \& Blaszczynski, A. (2006). Personality and self-reported use of mobile phones for games. Cyber Psychology \& Behavior, 9(6), 753-758.

Phillips, S. (2010). An app for everything. License! Global, 13(4), 140,142.

Tabachnick, B. G. \& Fidell, L. S. (2000). Using multivariate statistics, 4th ed. Boston: Allyn \& Bacon.

U.S. mobile local ad revenue to grow from $\$ 404$ million in 2010 to $\$ 2.8$ billion in 2015. (2011). BIA/Kelsey. Retrieved from http://www.biakelsey.com/Advisory-Services/Social-Local-Media.

Watson, D. \& Clark, L. A. (1997). Extraversion and its positive emotional core. R. Hogan, J. Johnson, S. Briggs, eds. Handbook of Personality Psychology. Academic Press, San Diego, 767-793.

Weintraub, S. (2010). 2011 will be the year android explodes. Retrieved from http://tech.fortune.cnn.com/2010/12/22/2011-will-be-the-year-android-explodes.

Whitney, L. (2011). Smartphones to dominate PCs in Gartner Forecast. Retrieved from http://news.cnet.com/8301-1001_3-10434760-92.html. 